Article

\title{
Determination of Hydrophilic UV Filters in Real Matrices Using New-Generation Bar Adsorptive Microextraction Devices
}

\author{
Alessandra Honjo Ide and José Manuel Florêncio Nogueira * \\ Centro de Química e Bioquímica e Centro de Química Estrutural, Faculdade de Ciências, Universidade de \\ Lisboa, 1749-016 Lisboa, Portugal; alessandrahide@gmail.com \\ * Correspondence: nogueira@fc.ul.pt; Tel.: +351-217500899
}

Received: 29 May 2019; Accepted: 19 August 2019; Published: 25 September 2019

\begin{abstract}
In the present contribution, new-generation bar adsorptive microextraction devices combined with microliquid desorption, followed by high-performance liquid chromatography-diode array detection (BA $\mu \mathrm{E}-\mu \mathrm{LD} / \mathrm{HPLC}-\mathrm{DAD})$ are proposed for the determination of two very polar ultraviolet (UV) filters (2-phenylbenzimidazole-5-sulfonic acid (PBS) and 5-benzoyl-4hydroxy-2-methoxybenzenesulfonic acid (BZ4)) in aqueous media. Different sorbents were evaluated as $\mathrm{BA} \mu \mathrm{E}$ coating phases, in which polystyrene-divinylbenzene polymer showed the best selectivity for the analysis of both UV filters, with average extraction efficiency of $61.8 \pm 9.1 \%$ for PBS and $69.5 \pm 4.8 \%$ for BZ4. The validated method showed great reproducibility for the analysis of PBS and BZ4 UV filters, providing suitable limits of detection $\left(0.04 \mu \mathrm{g} \mathrm{L}^{-1}\right.$ and $\left.0.20 \mu \mathrm{g} \mathrm{L}^{-1}\right)$, as well as good linear dynamic ranges $\left(0.16-16.0\right.$ and $\left.0.8-80.0 \mu \mathrm{g} \mathrm{L}^{-1}\right)$, respectively. The proposed methodology was applied for monitoring the target analytes in several real matrices, including tap, sea, and estuarine waters, as well as wastewater samples. Despite some matrix effects being observed for some real samples, good selectivity and linearity were obtained. The present contribution showed an innovative analytical cycle that includes the use of disposable devices, which make BA $\mu \mathrm{E}$ much more user-friendly and suitable for the routine work, being a remarkable analytical alternative for trace analysis of priority compounds in real matrices.
\end{abstract}

Keywords: bar adsorptive microextraction; floating sampling technology; high-performance liquid chromatography; polar UV filters; real matrices

\section{Introduction}

In the last decades, many improvements have been introduced in the field of sample preparation, aiming at simplification, miniaturization, easy manipulation, as well as the reduction of the use of toxic organic solvents, in compliance with the green analytical chemistry (GAC) principles. In this context, the sorption-based techniques have played an important role, mainly for trace analysis of complex matrices. In this regard, solid phase microextraction (SPME) [1], stir bar sorptive extraction (SBSE) [2], and, more recently, bar adsorptive microextraction $(\mathrm{BA} \mu \mathrm{E})$ [3,4] are good examples of effective sample-enrichment approaches. In $\mathrm{BA} \mu \mathrm{E}$, a bar-shaped polypropylene device $(7.5 \mathrm{~mm}$ in length and $3 \mathrm{~mm}$ in diameter) coated with a convenient sorbent phase is used, simultaneously with a conventional Teflon magnetic stirring bar at the bottom of the sampling flask. This technique operates under the floating sampling technology mode, which uses an analytical device lighter in weight in comparison with water density. The $\mathrm{BA} \mu \mathrm{E}$ devices are easily lab-made by coating the polypropylene support bars with a convenient adhesive, where the sorbent materials $(<5 \mathrm{mg})$ are fixed. BA $\mu \mathrm{E}$ is very cost-effective, and the great advantage over other sorption-based methodologies is that the analytical 
devices can be easily coated with the most selective sorbent phases, according to the characteristics of the target analytes. Furthermore, this technology is also in compliance with GAC principles, needing just around $100 \mu \mathrm{L}$ of an appropriate organic solvent during the back-extraction stage, performed through liquid desorption (LD). In a previous work [5], novel improvements were introduced in this technique, by designing new-generation $\mathrm{BA} \mu \mathrm{E}$ devices in order to reduce the number of steps involved during the back-extraction stage. It allowed the implementation of an innovative analytical cycle, with an effective microextraction stage together with a back-extraction stage performed in "only single LD step", for interface enhancement with the instrumental systems. From the analytical point of view, the new-generation $\mathrm{BA} \mu \mathrm{E}$ approach is user-friendly, as well as much more competitive for the routine work over other well-established microextraction techniques. Furthermore, due to the simplicity, eco-friendliness and cost-effectiveness involved, the reutilization is not considered in this novel analytical approach. To show the versatility of the new-generation devices recently introduced [5], the present contribution aims to apply them to monitor trace levels of highly polar compounds, such as hydrophilic ultraviolet (UV) filters in real samples.

UV filters are a large group of chemical compounds used to block or absorb UV light and protect the skin from the harmful effects of sun radiation. They are extensively present in a variety of personal care products, such as sunscreen lotions, skin care, facial makeup, and lip care products. These compounds are considered persistent pollutants once they are continuously released into the aquatic ecosystems through recreational aquatic activities or industrial and urban wastewaters. As a result, UV filters have been found at trace levels in several environmental matrices, mainly in surface [6], sea [7], as well as tap [8] waters, and their effects and consequences are issues of increasing concern. Numerous reports can be found in the literature regarding the determination of lipophilic UV filters from environmental water samples using microextraction techniques [9-11]. Meanwhile, few studies aim at the analysis of very polar UV filters and, most of them, use non-green analytical techniques such as solid phase extraction [12,13]. Yet, only one paper can be found in the literature using a miniaturized technique for the extraction of these hydrophilic UV filters compounds, the stir bar sorptive-dispersive microextraction mediated by magnetic nanoparticles-nylon 6 composite [14]. Although it is efficient, this methodology requires the composite synthesis in three steps, including the synthesis of the nanoparticles, followed by coating with silica, and finally the synthesis of the polymeric network with the nanoparticles, which takes many hours and requires several chemicals.

In this work, the new-generation $\mathrm{BA} \mu \mathrm{E}$ devices combined with high-performance liquid chromatography-diode array detection (BA $\mu \mathrm{E}-\mu \mathrm{LD} / \mathrm{HPLC}-\mathrm{DAD}$ ) is applied for the determination of two highly polar UV filters (2-phenyl-5-benzemidazolesulfonic acid (PBS) and 5-benzoyl-4-hydroxy-2-methoxy-benzenesulfonic acid, also known as benzophenone-4 (BZ4)) (Table 1) in real matrices. The optimization, validation, and application of the proposed analytical methodology to several types of matrices are fully discussed.

Table 1. Chemical structures, $\log K_{\mathrm{OW}}$ and $\mathrm{p} K_{\mathrm{a}}$ of the two ultraviolet (UV) filters under study. PBS: 2-phenyl-5-benzemidazolesulfonic acid. BZ4: 5-benzoyl-4-hydroxy-2-methoxy-benzenesulfonic acid.

UV Filter




\section{Materials and Methods}

\subsection{Reagents, Standards, and Samples}

Analytical standards of PBS (96\%) and BZ4 ( $\geq 97.0 \%)$ were purchased from Sigma Aldrich (Steinheim, Germany). Methanol (MeOH, 99.8\%) and acetic acid (99.5\%) were obtained from Carlo Erba (Arese, Italy), sodium chloride $(\mathrm{NaCl}, 99.5 \%)$ was provided from Merck (Darmstadt, Germany), sodium hydroxide ( $\mathrm{NaOH}, 98.0 \%$ ) was purchased from BDH Chemicals (London, UK), hydrochloric acid $(\mathrm{HCl}, 37 \%)$ was provided from Panreac (Barcelona, Spain). Ultra-pure water was obtained from Mili-Q water Milipore purification systems (Billerica, MA, USA). Stock solutions of individual UV filters (1000 $\mathrm{mg} \mathrm{L}^{-1}$ ) were prepared in $\mathrm{MeOH}$, and standard mixtures for instrumental calibration were prepared by appropriated dilution of the previous stock solutions. The polymeric phases used were $N$-vinylpyrrolidone-divinylbenzene (HLB; particle size 30 , surface area $810 \mathrm{~m}^{2} \mathrm{~g}^{-1}$ and $\mathrm{pH}$ stability 1-14, Waters, Milford, MA, USA) and polystyrene-divinylbenzene (PS-DVB; particle size 40-120 $\mu \mathrm{m}$, surface area $1200 \mathrm{~m}^{2} \mathrm{~g}^{-1}$ and $\mathrm{pH}$ stability: 1-13, Merck, Kenilworth, NJ, USA). The activated carbons, AC1 (surface area $1400 \mathrm{~m}^{2} \mathrm{~g}^{-1}$; $\mathrm{pH}_{\text {PZC }}$ : 2.2) and AC2 (surface area $1400 \mathrm{~m}^{2} \mathrm{~g}^{-1}$; $\mathrm{pH}_{\mathrm{PZC}}$ : 6.4) were obtained from Salmon \& Cia (Lisbon, Portugal). All water samples were obtained in the metropolitan area of Lisbon (Portugal). The tap water samples were obtained from our lab; the estuarine and sea water samples from the coast, and the wastewater samples from Alcantara wastewater treatment plant.

\subsection{Experimental Set-Up}

\subsubsection{Optimization Assays}

The new generation of BA $\mu \mathrm{E}$ devices were prepared "in house" by using nylon supports having bar-shaped geometry $(7.5 \mathrm{~mm}$ in length and $1.0 \mathrm{~mm}$ in diameter) and an adhesive film coated with the powdered sorbents, previously cleaned with ultra-pure water. The detailed description of the devices manufacturing can be consulted in previous reports [3,5]. For the optimization assays, $25 \mathrm{~mL}$ of ultra-pure water spiked with the working standard solution $\left(8.0 \mu \mathrm{g} \mathrm{L}^{-1}\right.$ for PBS and $40.0 \mu \mathrm{g} \mathrm{L}^{-1}$ for BZ4), a $\mathrm{BA} \mu \mathrm{E}$ device, and a conventional Teflon magnetic bar were introduced into glass sampling flasks. The microextraction stage was performed in a univariate optimization strategy using a multipoint agitation plate (Variomag H + P Labortechnik AG Multipoint 15, Germany) at room temperature $\left(25^{\circ} \mathrm{C}\right)$, under the floating sampling technology mode. Parameters such as stirring rate $(750,1000$, and $1250 \mathrm{rpm})$, equilibrium time $(1,2,4,6$, and $16 \mathrm{~h})$, matrix $\mathrm{pH}(\mathrm{HCl} / \mathrm{NaOH} ; 1.0,2.0,4.0,6.0$, and 8.0), organic modifier $(\mathrm{MeOH} ; 0,5,10$, and $15 \%, v / v)$, and ionic strength $(\mathrm{NaCl} ; 0,5,10,15,20$, and $30 \%, w / v)$ were systematically studied in triplicate. The back-extraction stage was performed using a single LD step, in which the devices were removed from the sampling flasks using clean tweezes and placed directly into inserts containing $100 \mu \mathrm{L}$ of the stripping solvent (HPLC mobile phase) inside glass vials $(2 \mathrm{~mL})$, ensuring their total immersion. Then the vials were sealed using a handy crimper prior to ultrasonic treatment at room temperature. To evaluate the best LD conditions, different desorption times (10, 15, 30, 45, and $60 \mathrm{~min})$ using ultrasonic treatment were systematically studied in triplicate. After the back-extraction assays, the vials became ready for analysis and were placed into the autosampler trays of the HPLC-DAD system. Blank assays were also performed in triplicate, using the procedure described above without spiking.

\subsubsection{Validation Assays}

For the method validation experiments, ultra-pure water samples were spiked with the working standard solutions of the UV filters at the desired concentrations $\left(0.16-16.0 \mu \mathrm{g} \mathrm{L}^{-1}\right.$ for PBS and $0.8-80.0 \mu \mathrm{g} \mathrm{L}^{-1}$ for BZ4), and the extraction and back-extraction assays were performed in triplicate, as described above, under experimental optimized conditions. 


\subsubsection{Real Samples Assays}

The proposed methodology was applied for monitoring the two UV filters in real matrices using the standard addition method (SAM). For tap, surface, estuarine, sea water, and wastewater assays, $25 \mathrm{~mL}$ of sample, previously filtered with paper filters (125 mm of diameter, Cat. No. 1001 125, Whatman, UK), were spiked with the working standards solutions $\left(0.4-8.0 \mu \mathrm{g} \mathrm{L}{ }^{-1}\right.$ for PBS and 2.0-40.0 $\mu \mathrm{g} \mathrm{L}^{-1}$ for BZ4) and performed in triplicate using the optimized procedure, as described before. Blank assays were also analyzed without spiking.

\subsection{Instrumental Set-Up}

The analyses were performed using a HPLC-DAD Agilent 1100 Series system (Agilent Technologies, Waldbronn, Germany), constituted by vacuum degasser (G1322A), quaternary pump (G1311A), autosampler (G1313A), thermostated column compartment (G1316A), and a diode array detector (G1315B). The data acquisition and instrumental control were performed by the software LC3D Chemistation (versions Ver. A. 10.02, Agilent Technologies, Germany). The separation of the analytes was performed on a Kinetex C18 column $(150 \times 4.6 \mathrm{~mm}, 2.6 \mu \mathrm{m}$; Phenomenex, Torrance, CA, USA). The mobile phase consisted of an isocratic mixture of $\mathrm{MeOH}$ and $20 \mathrm{mM}$ acetate buffer $(\mathrm{pH} 4.75$ at a mixing ratio of $30: 70(v / v))$ with a flow rate of $0.5 \mathrm{~mL} \mathrm{~min}^{-1}$. The column temperature was maintained constant at $50{ }^{\circ} \mathrm{C}$. The injection volume was $20 \mu \mathrm{L}$, with a draw speed of $200 \mu \mathrm{L}$ $\mathrm{min}^{-1}$. The detector was set at $300 \mathrm{~nm}$. For identification purposed, the retention time and peak purity were compared with the UV/vis spectral reference data of each compound. For extraction efficiency calculation, peak areas obtained from each assay were compared with the peak areas of standard controls used for spiking. For quantification purposes on real matrices, calibration plots from the SAM were used.

\section{Results and Discussion}

\subsection{HPLC-DAD Optimization}

In the present contribution, two UV filters (PBS and BZ4, Table 1) were studied as target analytes. From the very beginning, the HPLC-DAD instrumental conditions were evaluated, such as UV/vis absorbance spectra, retention times, and resolution. A wavelength at $300 \mathrm{~nm}\left(\lambda_{\max }\right)$ was selected as it maximized the DAD signal for both target compounds. Since the ionization equilibrium is temperature dependent and the two UV filters are very polar and ionizable compounds, temperature control can improve the HPLC selectivity [14]. Therefore, the column temperature was maintained constant at $50{ }^{\circ} \mathrm{C}$, once better symmetrical peak shapes were achieved. Therefore, optimized HPLC-DAD conditions resulted in good resolution in a suitable analytical time (11.0 $\mathrm{min})$. Instrumental sensitivity was evaluated through the limits of detection (LODs) and quantification (LOQs), obtained after the injection of diluted standard mixtures and calculated with a signal-to-noise ratio $(\mathrm{S} / \mathrm{N})$ of 3 and 10 , respectively. From the data obtained, instrumental LODs and LOQs of 20 and $100 \mu \mathrm{g} \mathrm{L}^{-1}$, as well as 60.0 and $300.0 \mu \mathrm{g} \mathrm{L}^{-1}$ were achieved, respectively. The instrumental calibration was assessed with standard mixtures ranging from 60.0 to $10,000 \mu \mathrm{g} \mathrm{L}^{-1}$ for PBS and 300.0 to $25,000 \mu \mathrm{g} \mathrm{L}^{-1}$ for BZ4, using six levels. The regression plots achieved showed good linearity responses $\left(r^{2}=0.9982\right.$ for PBS and 0.9996 for BZ4).

\subsection{Selection of the $B A \mu E$ Coating Phase}

One of the great advantages of the $\mathrm{BA} \mu \mathrm{E}$ technique is that we can easily choose the most convenient sorbent phase, according to the best selectivity for the analytes under study. Therefore, two polymers (HLB and PS-DVB) and two activated carbons (AC1 and AC2) were evaluated, and the results are depicted in Figure 1. From the data obtained, PS-DVB presented the best extraction efficiency among all sorbents tested. The polymers used are reversed-phase-type, retaining the analytes according to the particle size, surface area, and mechanisms involved. Thus, the presence of aromatic rings 
both in their network and in the molecules involved seems to favour $\pi-\pi$ and dipole-dipole-type interactions between them. Furthermore, the PS-DVB coating phase presented a better extraction efficiency, probably due to its higher surface area $\left(1200 \mathrm{~m}^{2} \mathrm{~g}^{-1}\right)$ when compared with the HLB polymer $\left(810 \mathrm{~m}^{2} \mathrm{~g}^{-1}\right)$. On the other hand, the activated carbons are porous solid materials that retain the solutes through electrostatic and/or dispersive interactions, according to the textural adsorption properties, as well as surface area and pore dimensions involved. Moreover, the interactions between the analytes and the sorbent are strongly influenced by the $\mathrm{pH}$ of the bulk solution. When the matrix $\mathrm{pH}$ is equal to the $\mathrm{pH}_{\mathrm{PZC}}$, the activated carbon surface becomes neutral, with equal number of positive and negative charges. If the value is lower than the $\mathrm{pH}_{\mathrm{PZC}}$, the activated carbon surface becomes positive and, if higher than the $\mathrm{pH}_{\mathrm{PZC}}$, turns into negative. At $\mathrm{pH} 2.0$, the sulfonated groups of the analytes are deprotonated $\left(\mathrm{p} K_{\mathrm{a}}<1\right)$, wherein $\mathrm{AC} 1$ and $\mathrm{AC} 2$ are neutral and positively charged, respectively, in which electrostatic interactions may occur between both analytes and AC2. However, the attractive forces are probably, in some cases, so strong that both analytes are still retained in the activated carbon network, even after the back-extraction stage under ultrasonic treatment, resulting in lower extraction efficiency.

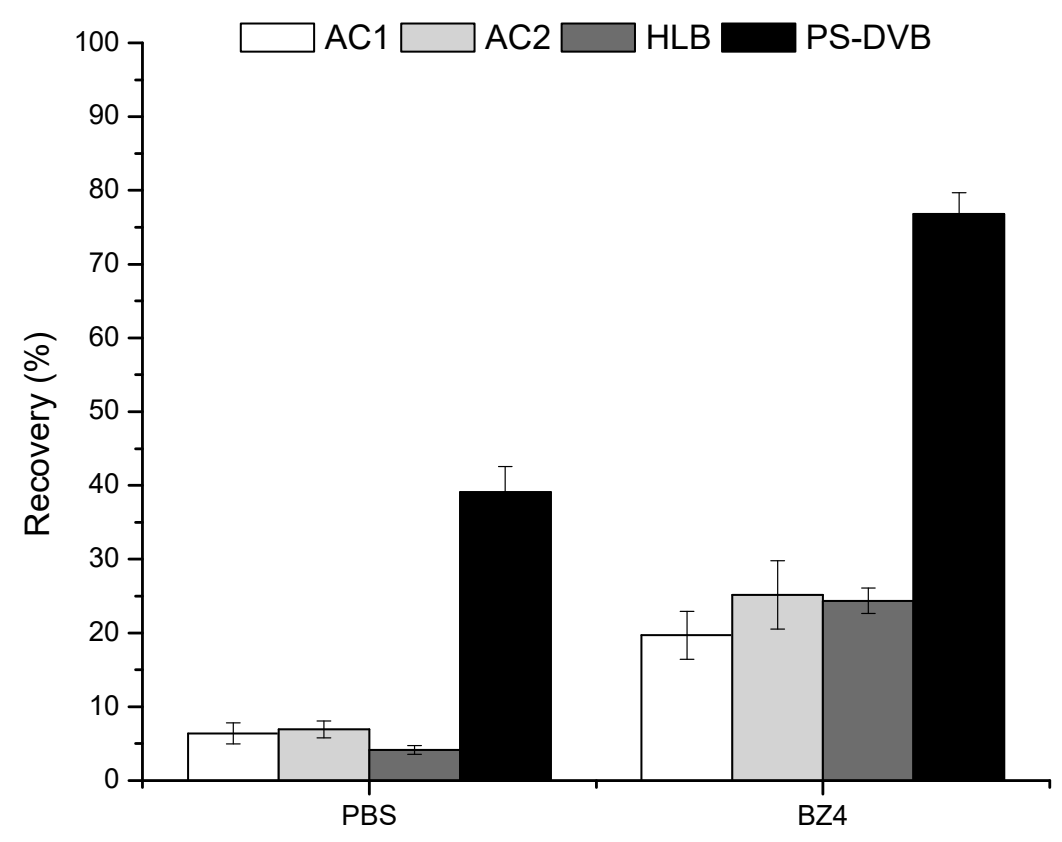

Figure 1. Average extraction efficiency obtained by BA $\mu \mathrm{E}-\mu \mathrm{LD} / \mathrm{HPLC}-\mathrm{DAD}$ using different activated carbons and polymers sorbent phases for the microextraction of PBS and BZ4 in ultra-pure water, using standard experimental conditions. The error bars represent the standard deviation of 3 replicates.

\subsection{Back-Extraction Stage}

The back-extraction stage was always limitative in $\mathrm{BA} \mu \mathrm{E}$, since substantial manipulation, many times up to six steps (i.e., removing the device from the sampling flask, placing the device into a convenient organic solvent inside a vial, sonication treatment, removing the device from the vial, evaporating the organic microextract until dryness, solvent switch) were required. However, the implementation of an innovative analytical cycle allowed negligible manipulation during the back-extraction stage, which is now performed in "only single LD step", making BA $\mu$ E a much more simple approach. In this technique, after the microextraction stage, the devices were placed into glass vial inserts, having $100 \mu \mathrm{L}$ of mobile phase to desorb the target analytes, in which, after sealing and ultrasonic treatment, became ready for instrumental analysis. Therefore, desorption times of $10,15,30$, and $60 \mathrm{~min}$ were assayed, in which the results (data not shown) proved that $10 \mathrm{~min}$ of ultrasonic treatment was enough to desorb both UV filters from the PS-DVB sorbent phase. Besides the results obtained, the back-extraction stage showed to be very user-friendly, once the several 
steps of cumbersome manipulation were avoided. Since the analytical device has small dimensions $(7.5 \times 1.0 \mathrm{~mm})$, the desorption stage can be performed inside common glass vial inserts, having enough space for the needle of the conventional HPLC injection systems, with the possibility of automation for routine work. Moreover, due to the very easy preparation and low cost of the analytical devices, they are used only once, being discarded at the end of the sample analysis.

\subsection{Microextraction Stage}

Since $\mathrm{BA} \mu \mathrm{E}$ is a static microextraction technique, the equilibrium between the matrix and the sorbent phase depends on the affinity of each analyte to the PS-DVB polymer. Therefore, the main experimental conditions that may affect the microextraction stage, including the kinetic (extraction time and agitation speed) and thermodynamic ( $\mathrm{pH}$, ionic strength, and polarity of the matrix) parameters, were evaluated to achieve the best extraction efficiency for the two target analytes.

Since the beginning, it was noticed that $\mathrm{pH}$ is a very important parameter, as the UV filters under study are extremely hydrophilic compounds. Thus, the effect of the matrix $\mathrm{pH}$ was assessed, ranging from 1.0 to 8.0. As the extraction efficiency decreased with the increase of the $\mathrm{pH}$ (Figure 2a), $\mathrm{pH} 2.0$ was chosen for further studies. Due to the very low and even negative $\mathrm{p} K_{\mathrm{a}}$ values involved (Table 1 ), the analytes were deprotonated even in low values of $\mathrm{pH}$. However, maximum adsorption at more acidic $\mathrm{pH}$ values indicated that the low $\mathrm{pH}$ contributed to the increase of $\mathrm{H}^{+}$ions on the adsorbent surface, resulting in strong electrostatic attraction between the positively charged anionic PS-DVB surface and the deprotonated analyte ions. Subsequently, the equilibrium time and agitation speed were evaluated, where the former has a great effect on the microextraction kinetics, as it may limit the distribution of the target compounds between the matrix and the sorbent phase. On the other hand, the later influences the mass transfer (diffusion) of both UV filters towards the analytical device through the floating sampling technology approach. Therefore, equilibrium times between 1 and $16 \mathrm{~h}$ were studied, in which the results obtained revealed that $16 \mathrm{~h}$ was needed (Figure $2 \mathrm{~b}$ ), ensuring the best equilibrium conditions. Besides the slow kinetics demanding a substantial period of equilibrium time, this analytical approach can be performed overnight without any special requirements. Agitation speed was then assessed through assays performed at 750, 1000, and $1250 \mathrm{rpm}$, and, according to the data obtained (data not shown), an agitation speed of $750 \mathrm{rpm}$ provided much higher stability on the analytical devices during the microextraction process and was chosen for the subsequent studies.

Finally, the matrix characteristics such as ionic strength and polarity were also evaluated, as they can significantly affect the performance of the sample enrichment. To check the effect of the ionic strength, assays were performed, with the addition of $\mathrm{NaCl}$ having concentrations ranging from 0 to $30 \%$. From the data achieved (Figure 2c), the increment of the ionic strength up to $20 \%$ helped the microextraction process, decreasing the solubility of both organic compounds in aqueous media ("salting-out effect"), favoring their migration towards the sorbent phase. On the other hand, the matrix polarity was studied through the addition of $\mathrm{MeOH}$ up to $15 \%$. The data obtained in Figure $2 \mathrm{~d}$ showed that the average recoveries for both UV filters decreased significantly with the increment of the $\mathrm{MeOH}$ content, once it favored their solubility in the bulk solution. 

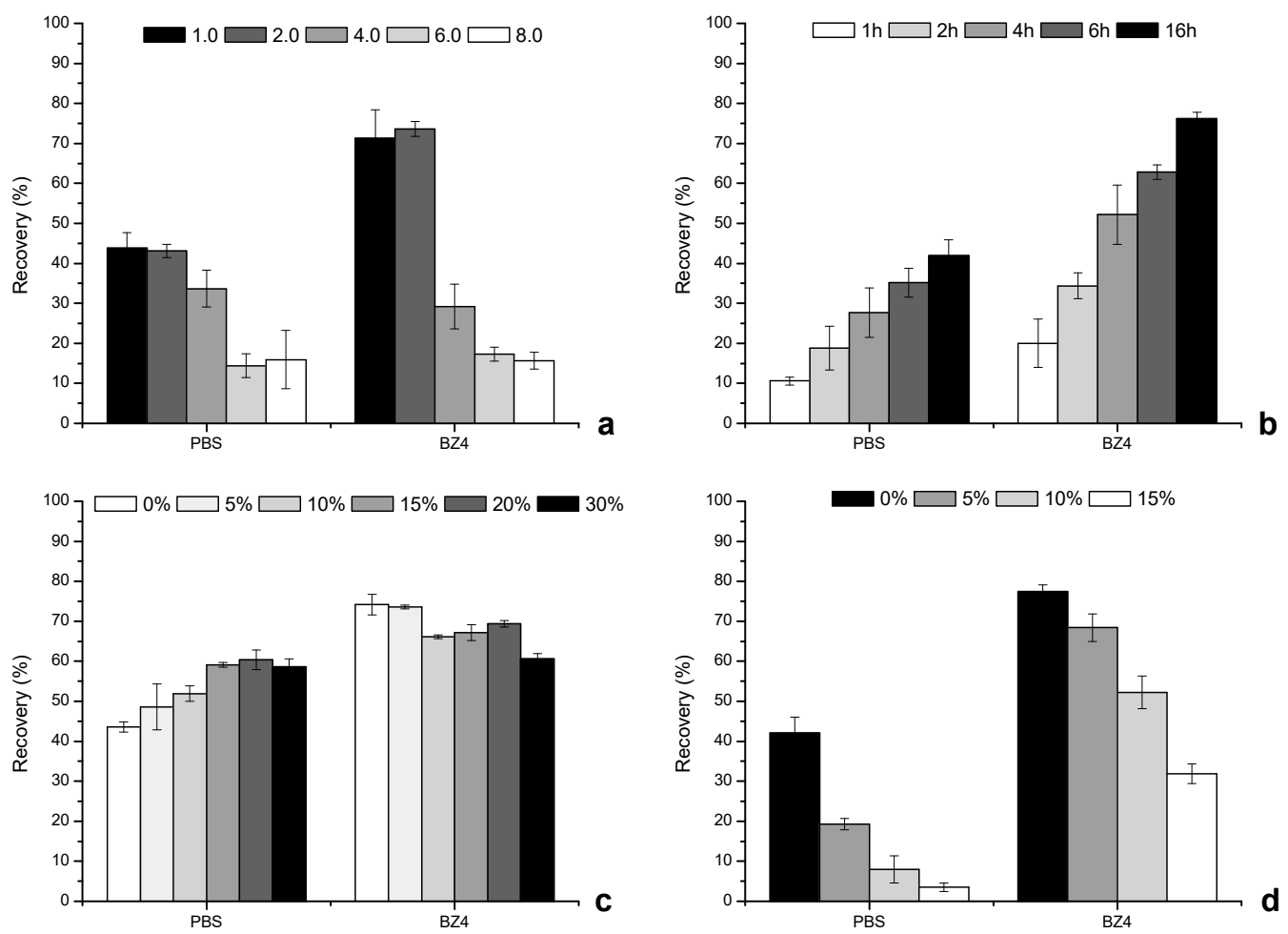

Figure 2. Effect of $\mathrm{pH}(\mathbf{a})$, equilibrium time (b), ionic strength (c), and matrix polarity (d) on the microextraction efficiency for both UV filters in ultra-pure water. The error bars represent the standard deviation of three replicates.

\subsection{Method Validation}

The optimized experimental conditions achieved for monitoring the UV filters in aqueous media

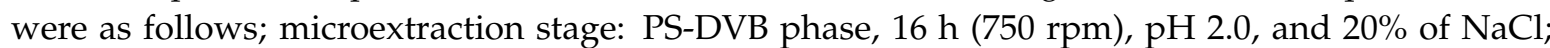
back-extraction stage: mobile phase $(100 \mu \mathrm{L}), 10 \mathrm{~min}$ under sonication. In order to validate the proposed methodology, assays were performed on $25 \mathrm{~mL}$ of ultra-pure water samples spiked with the target compounds at concentrations ranging from 0.16 to $16.0 \mu \mathrm{g} \mathrm{L}^{-1}$ for PBS and 0.80 to $80.0 \mu \mathrm{g} \mathrm{L}-1$ for BZ4. The analytical limits were also evaluated and calculated, with $\mathrm{S} / \mathrm{N}$ of 3 and 10, respectively. Table 2 summarizes the average extraction efficiency $(61.8 \pm 9.1 \%$ for PBS and $69.5 \pm 4.8 \%$ for BZ4), LODs $\left(0.04 \mu \mathrm{g} \mathrm{L}{ }^{-1}\right.$ for PBS and $0.20 \mu \mathrm{g} \mathrm{L}-1$ for BZ4), LOQs $\left(0.16 \mu \mathrm{g} \mathrm{L}-1\right.$ for PBS and $0.80 \mu \mathrm{g} \mathrm{L}^{-1}$ for BZ4), and determination coefficients ( 0.9985 for PBS and 0.9993 for BZ4) obtained for the proposed methodology to monitor the two UV filters, under optimized experimental conditions. Repeatability studies were then evaluated in terms of interday (three replicates a day in three consecutive days) and intraday (five replicates performed in the same day) assays, in which the data obtained showed RSD below $12 \%$. From the validation data, the proposed methodology performed by BA $\mu$ (PS-DVB)- $\mu L D / H P L C-D A D$ showed remarkable analytical performance for trace analysis of the two UV filters under study.

Table 2. Average recoveries, LODs (limits of detection), LOQs (limits of quantification), linear dynamic ranges, determination coefficients $\left(r^{2}\right)$, and slopes obtained for the two UV filters by BA $\mu$ E(PS-DVB)- $\mu L D / H P L C-D A D$, under optimized experimental conditions.

\begin{tabular}{ccccccc}
\hline UV Filter & $\begin{array}{c}\text { Extraction } \\
\text { Efficiency } \\
(\boldsymbol{\%})\end{array}$ & $\begin{array}{c}\text { LOD } \\
\left(\mu \mathbf{g ~ L}^{-1}\right)\end{array}$ & $\begin{array}{c}\text { LOQ } \\
\left(\mu \mathbf{g ~ L}^{-1}\right)\end{array}$ & $\begin{array}{c}\text { Dynamic } \\
\text { Range }\end{array}$ & $r^{2}$ & Slope \\
\hline PBS & $61.8 \pm 9.1$ & 0.04 & 0.16 & $0.16-16.0$ & 0.9985 & 9.25 \\
\hline BZ4 & $69.5 \pm 4.8$ & 0.20 & 0.80 & $0.80-80.0$ & 0.9993 & 2.47 \\
\hline
\end{tabular}


By comparing the proposed methodology with other passive sampling approaches, such as stir bar sorptive-dispersive microextraction (SBSDME; recoveries yields of $58 \pm 2$ and $55 \pm 5 \%$ and LODs of $2.8 \mu \mathrm{g} \mathrm{L}^{-1}$ and $1.6 \mu \mathrm{g} \mathrm{L}^{-1}$ for PBS and BZ4, respectively) [14], BA $\mu \mathrm{E}$ presented much higher extraction efficiency and lower LODs, being an effective analytical alternative for monitoring both UV filters in aqueous media.

The presence of the sulfonic groups in the chemical structure of both target analytes makes them highly soluble, hindering the corresponding microextraction. Consequently, few studies are reported in the literature regarding the analysis of very hydrophilic UV filters, and most of them use SPE as sample enrichment, which is more expensive, requires larger sample volumes, and is not eco-friendly. In short, the methodology proposed herein is a remarkable contribution as an alternative analytical methodology for monitoring trace levels of polar UV filters in aqueous media, besides being eco-friendly, user-friendly, very cost-effective and in compliance with the routine work.

\subsection{Application to Real Matrices}

In order to demonstrate the reliability of the proposed methodology for real matrices, BA $\mu$ E(PS-DVB)- $\mu L D / H P L C-D A D$ was applied to monitor both hydrophilic UV filters in tap, estuarine, and sea water, as well as wastewater samples. For such purpose and in order to suppress possible matrix interferences, SAM was used for quantitative purposes, by spiking the samples with four working standards, ranging from 0.4 to $8.0 \mu \mathrm{g} \mathrm{L}{ }^{-1}$ for PBS and 2.0 to $40.0 \mu \mathrm{g} \mathrm{L}{ }^{-1}$ for BZ4. Blank assays were also performed without spiking to ensure maximum control of the analytical methodology. As expected, in the water matrices studied, any of the analytes were detected (<LODs). As already reported in the literature [14], significant matrix effects were observed during the study of the real matrices, although good selectivity and linearity were achieved, with determination coefficients higher than 0.9940 (BZ4, wastewater sample), obtained from the regression plots (Table 3). Even so, the methodology proposed showed to be influenced by the substantial matrix effects observed, in particular, for the more complex samples, i.e., sea and estuarine water, as well as wastewater. As the UV filters involved are extremely hydrophilic, the higher is the complexity of the matrix, the lower is the average extraction efficiency. For instance, the sea and the estuarine samples studied presented efficiencies which were three-quarters of that obtained for ultra-pure water, and the wastewater presented about one-third. Figure 3 depicts chromatogram profiles obtained from assays performed on spiked $\left(4.0 \mu \mathrm{g} \mathrm{L}{ }^{-1}\right.$ for PBS and $20.0 \mathrm{~L}^{-1}$ for BZ4) ultra-pure (a), tap (b), sea (c), and estuarine (d) waters, as well as wastewater (e) samples, in which very good selectivity is noticed.

Table 3. Determination coefficients $\left(r^{2}\right)$, slopes, and contents obtained for the two UV filters by $\mathrm{BA} \mu \mathrm{E}(\mathrm{PS}-\mathrm{DVB})-\mu \mathrm{LD} / \mathrm{HPLC}-\mathrm{DAD}$ in several real matrices, under optimized experimental conditions.

\begin{tabular}{|c|c|c|c|c|}
\hline UV Filter & Tap Water & Sea Water & Estuarine Water & Wastewater \\
\hline & \multicolumn{4}{|c|}{$r^{2}$} \\
\hline PBS & 0.9999 & 0.9998 & 0.9975 & 0.9942 \\
\hline \multirow[t]{2}{*}{ BZ4 } & 0.9998 & 0.9998 & 0.9994 & 0.9940 \\
\hline & \multicolumn{4}{|c|}{ Slope } \\
\hline PBS & 15.06 & 10.21 & 9.25 & 5.25 \\
\hline \multirow[t]{2}{*}{ BZ4 } & 4.28 & 2.69 & 2.47 & 1.10 \\
\hline & \multicolumn{4}{|c|}{ Content $\left(\mathrm{mg} \mathrm{g}^{-1}\right)$} \\
\hline PBS & $<\mathrm{LOD}$ & $<\mathrm{LOD}$ & $<\mathrm{LOD}$ & $<\mathrm{LOD}$ \\
\hline BZ4 & $<\mathrm{LOD}$ & $<\mathrm{LOD}$ & $<\mathrm{LOD}$ & $<\mathrm{LOD}$ \\
\hline
\end{tabular}



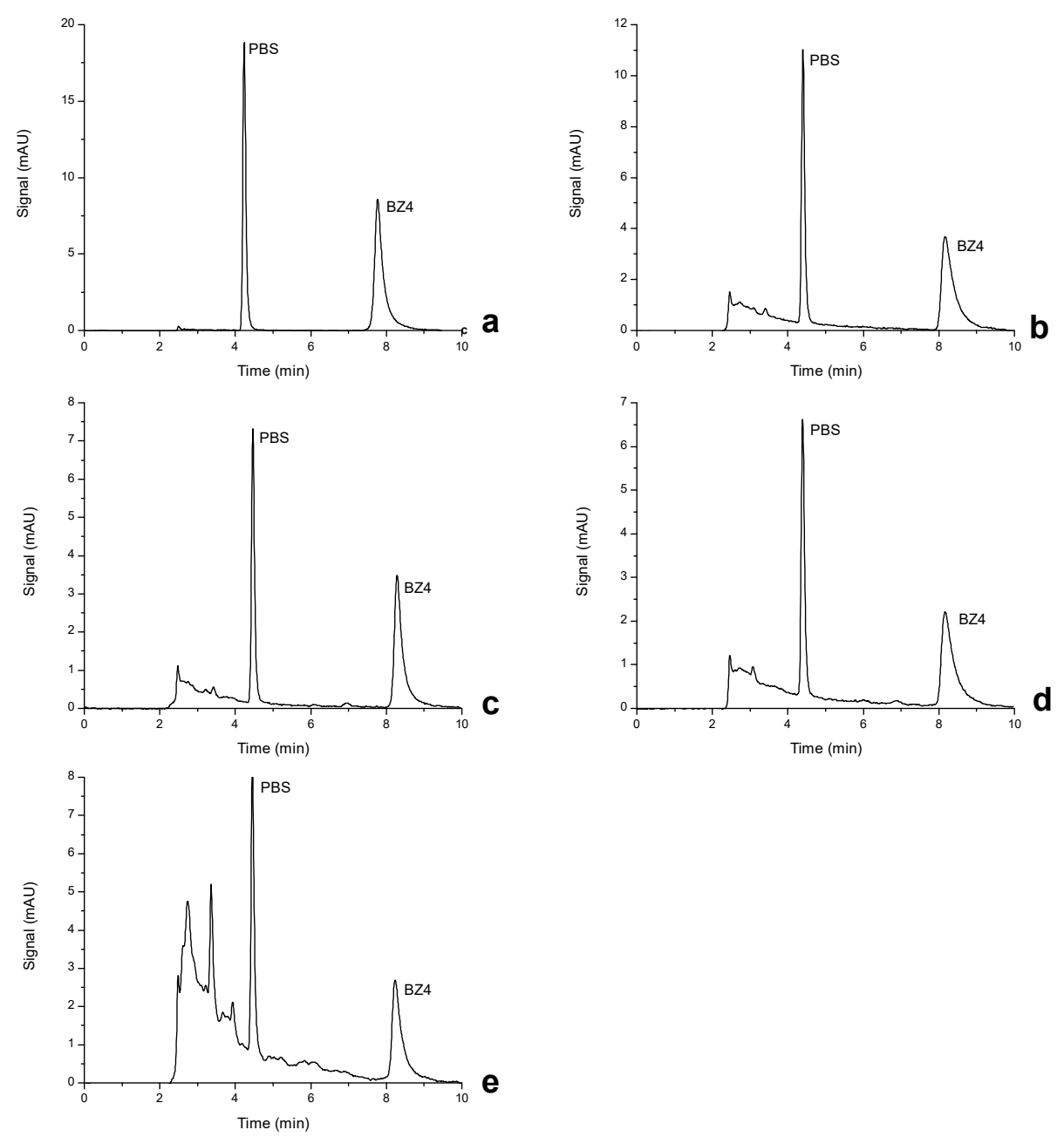

Figure 3. Chromatogram profiles obtained from assays performed in spiked ultra-pure (a), tap (b), sea (c) and estuarine water (d), as well as wastewater (e) samples by BA $\mu$ E(PS-DVB)- $\mu \mathrm{LD} / \mathrm{HPLC}-\mathrm{DAD}$, under optimized experimental conditions.

\section{Conclusions}

The proposed methodology uses the new-generation $\mathrm{BA} \mu \mathrm{E}$ devices for trace analysis of two polar UV filters (2-phenyl-5-benzemidazolesulfonic acid and 5-benzoyl-4-hydroxy-2-methoxybenzenesulfonic acid) in aqueous media. It was fully optimized, validated, and applied to real samples. An innovative analytical cycle that includes the use of disposable devices for an effective microextraction stage together with a back-extraction stage performed in "only single LD step", makes $\mathrm{BA} \mu \mathrm{E}$ still more user-friendly, eco-friendly, as well as dedicated for routine analysis. Under optimized experimental conditions, good extraction efficiency, suitable detection limits and precision, as well as convenient linear dynamic ranges were obtained. From the data achieved, BA $\mu$ E presents several advantages, such as the simple preparation of the analytical devices, the possibility to choose the best sorbent phase according to the characteristics of the target analytes, the low cost involved, the easy manipulation, as well as the ability to use negligible amounts of organic solvents, in compliance with GAC principles. In short, this approach is a remarkable analytical alternative for trace analysis of UV filters in aqueous media over other well-established microextraction techniques.

Author Contributions: Both authors contributed substantially to the work reported. A.H.I.: experimental, data analysis, writing and J.M.F.N.: supervision, writing and reviewing.

Funding: This research was funded by “Coordenação de Aperfeiçoamento de Pessoal de Nível Superior (CAPES BEX 0394-14-9) and "Fundação para a Ciência e a Tecnologia" (UID/MULTI/00612/2013). 
Acknowledgments: The authors wish to thank "Coordenação de Aperfeiçoamento de Pessoal de Nível Superior" (Brazil) for the Ph.D. grant (CAPES BEX 0394-14-9) and "Fundação para a Ciência e a Tecnologia" (Portugal) for funding (UID/MULTI/00612/2013).

Conflicts of Interest: The authors have declared no conflict of interest.

$\begin{array}{ll}\text { Abbreviations } \\ \text { BA } \mu \mathrm{E} & \text { bar adsorptive microextraction } \\ \text { BZ4 } & \text { 5-benzoyl-4-hydroxy-2-methoxy-benzenesulfonic acid } \\ \text { DAD } & \text { diode array detector } \\ \text { GAC } & \text { green analytical chemistry } \\ \text { LD } & \text { liquid desorption } \\ \text { MeOH } & \text { methanol } \\ \text { PBS } & \text { 2-phenyl-5-benzemidazolesulfonic acid } \\ \text { PS-DVB } & \text { polystyrene-divinylbenzene } \\ \text { SAM } & \text { standard addition method } \\ \text { SBSE } & \text { stir bar sorptive extraction } \\ \text { SPME } & \text { solid phase microextraction }\end{array}$

\section{References}

1. Arthur, C.L.; Pawliszyn, J. Solid phase microextraction with thermal desorption using fused silica optical fibers. Anal. Chem. 1990, 62, 2145-2148. [CrossRef]

2. Baltussen, E.; Sandra, P. Stir bar sorptive extraction (SBSE), a novel extraction technique for aqueous samples: Theory and principles. J. Microcolumn. 1999, 11, 737-747. [CrossRef]

3. Neng, N.R.; Silva, A.R.M.; Nogueira, J.M.F. Adsorptive micro-extraction techniques-novel analytical tools for trace levels of polar solutes in aqueous media. J. Chromatogr. A 2010, 1217, 7303-7310. [CrossRef] [PubMed]

4. Nogueira, J.M.F. Novel sorption-based methodologies for static microextraction analysis: A review on sbse and related techniques. Anal. Chim. Acta 2012, 757, 1-10. [CrossRef] [PubMed]

5. Ide, A.H.; Nogueira, J.M.F. New-generation bar adsorptive microextraction (BA $\mu \mathrm{E})$ devices for a better eco-user-friendly analytical approach-Application for the determination of antidepressant pharmaceuticals in biological fluids. J. Pharm. Biomed. Anal. 2018, 153, 126-134. [CrossRef] [PubMed]

6. Kameda, Y.; Kimura, K.; Miyazaki, M. Occurrence and profiles of organic sun-blocking agents in surface waters and sediments in japanese rivers and lakes. Environ. Pollut. 2011, 159, 1570-1576. [CrossRef] [PubMed]

7. Tsui, M.M.; Leung, H.W.; Wai, T.C.; Yamashita, N.; Taniyasu, S.; Liu, W.; Lam, P.K.; Murphy, M.B. Occurrence, distribution and ecological risk assessment of multiple classes of UV filters in surface waters from different countries. Water Res. 2014, 67, 55-65. [CrossRef] [PubMed]

8. Román, I.P.; Alberto, A.C.; Canals, A. Dispersive solid-phase extraction based on oleic acid-coated magnetic nanoparticles followed by gas chromatography-mass spectrometry for UV-filter determination in water samples. J. Chromatogr. A 2011, 1218, 2467-2475. [CrossRef] [PubMed]

9. Nguyen, K.T.; Scapolla, C.; Di Carro, M.; Magi, E. Rapid and selective determination of UV filters in seawater by liquid chromatography-tandem mass spectrometry combined with stir bar sorptive extraction. Talanta 2011, 85, 2375-2384. [CrossRef] [PubMed]

10. Zhang, Y.; Lee, H.K. Ionic liquid-based ultrasound-assisted dispersive liquid-liquid microextraction followed high-performance liquid chromatography for the determination of ultraviolet filters in environmental water samples. Anal. Chim. Acta 2012, 750, 120-126. [CrossRef] [PubMed]

11. Vila, M.; Celeiro, M.; Lamas, J.P.; Dagnac, T.; Llompart, M.; Garcia-jares, C. Determination of fourteen UV filters in bathing water by headspace solid-phase microextraction and gas chromatography-tandem mass spectrometry. Anal. Methods 2016, 8, 7069-7079. [CrossRef]

12. Negreira, N.; Rodríguez, I.; Ramil, M.; Rubí, E.; Cela, R. Solid-phase extraction followed by liquid chromatography-tandem mass spectrometry for the determination of hydroxylated benzophenone UV absorbers in environmental water samples. Anal. Chim. Acta 2009, 654, 162-170. [CrossRef] [PubMed] 
13. Bratkovics, S.; Sapozhnikova, Y. Determination of seven commonly used organic UV filters in fresh and saline waters by liquid chromatography-tandem mass spectrometry. Anal. Methods 2011, 3, 2943. [CrossRef]

14. Benedé, J.L.; Chisvert, A.; Giokas, D.L.; Salvador, A. Stir bar sorptive-dispersive microextraction mediated by magnetic nanoparticles-nylon 6 composite for the extraction of hydrophilic organic compounds in aqueous media. Anal. Chim. Acta 2016, 926, 63-71. [CrossRef] [PubMed]

(C) 2019 by the authors. Licensee MDPI, Basel, Switzerland. This article is an open access article distributed under the terms and conditions of the Creative Commons Attribution (CC BY) license (http://creativecommons.org/licenses/by/4.0/). 